\title{
Nestora Salgado García: un testimonio de resistencias ante la violencia patriarcal y la criminalización de los pueblos indígenas
}

\author{
NESTORA SALGADO GARCÍA Y ROSALVA AIIDA HERNÁNDEZ CASTILLO
}

Nestora Salgado García:

A Testimony of Resistance against Patriarchal Violence and the Criminalization of Indigenous Peoples

Nestora Salgado Garcia Coordinadora Regional de Autoridades Comunitarias, Olinalá, Guerrero, México arcoirisenelmar@yahoo.com.ar

\section{Rosalva Aída Hernández Castillo} Centro de Investigaciones y Estudios Superiores en Antropología SocialCiudad de México, México aidaher2005@gmail.com

Desacatos 57, mayo-agosto 2018, pp. 168-179 n los últimos tres años, el nombre de Nestora Salgado se ha convertido en un símbolo de resistencia para muchas mujeres que luchan contra la violencia patriarcal en varias regiones del continente y para las comunidades indígenas que reivindican sus sistemas de seguridad y justicia. La comandanta de la Policía Comunitaria de Olinalá, en el estado mexicano de Guerrero, fue considerada presa política por Amnistía Internacional. Se trata de una víctima más de la criminalización de los movimientos indígenas en el continente.

El 18 de marzo de 2016 fue liberada, después de dos años y ocho meses de prisión. Su liberación fue producto de la articulación de la lucha de sus abogados, Sandino y Leonel Rivero, en México; Alejandra Gonza, de la Universidad de Washington; la solidaridad nacional e internacional y la presión política ejercida por el Grupo de Trabajo sobre Detención Arbitraria de las Naciones Unidas.

Tuve el privilegio de conocer a Nestora Salgado, comandanta de la Coordinadora Regional de Autoridades Comunitarias (CRAC) de Guerrero, en la Torre Médica del Centro Femenil de Readaptación Social (Cereso) de Tepepan, en la Ciudad de México. Nestora fue trasladada a Tepepan de una cárcel de alta seguridad de Tepic, Nayarit, el 28 de mayo de 2015, después de una huelga de hambre que casi le cuesta la vida.

Llegué a este espacio penitenciario para trabajar con ella en su historia de vida. Se trataba de reconstruir su trayectoria de trabajo en la justicia comunitaria y su historia personal por medio de entrevistas a profundidad, para elaborar un peritaje antropológico, solicitado por sus abogados defensores. ${ }^{1}$ El objetivo de este informe pericial

1 Realicé los tres peritajes con el etnólogo Héctor Ortiz Elizondo. En el registro de las entrevistas de la Torre Médica de Tepepan conté con el apoyo de la historiadora Nancy Salais. Para una reflexión de mi experiencia en el activismo legal, que incluye la elaboración de este peritaje, véase Hernández (2017). Analizo los dilemas y paradojas específicos que enfrentamos en Hernández (inédito). 
era argumentar que los delitos que se le adjudicaban, como "secuestro" y "privación ilegal de la libertad", fueron detenciones legales realizadas en el marco de un sistema de justicia comunitaria indígena, reconocido por varias legislaciones estatales, nacionales e internacionales. Durante esos meses pude acercarme a esta mujer extraordinaria y entender las razones por las que sus acciones encontraron una respuesta tan violenta por parte de los poderes locales y sus cómplices regionales y nacionales.

Las casi 100 páginas de su historia de vida quedaron reducidas a tres informes periciales de 15 cuartillas cada uno, que dejaron fuera todas las metáforas, anécdotas y experiencias de dolor e impotencia que caracterizaban su narración. A pesar de nuestra preocupación por mantener una versión lo más fiel posible a su historia, el peritaje demandaba una extensión y un formato que implicaba imponer de nuevo el lenguaje de la legalidad. Este testimonio es un esfuerzo por recuperar con Nestora las historias y experiencias que quedaron fuera del peritaje y los nuevos retos que enfrenta en Estados Unidos, como exiliada política después de su liberación. Doy la palabra a Nestora para que nos comparta su historia.

\section{Crecer en Palito Redondo}

Me llamo Nestora Salgado García y nací el 28 de febrero de 1972, en el rancho de Palito Redondo, en el municipio de Olinalá, estado de Guerrero. Soy hija de don Fernando Salgado, hombre de conocimiento, médico tradicional reconocido en toda la región, y de doña Aurora García de Salgado, mujer trilingüe, hablante de mephaa, náhuatl y español, quien murió cuando yo tenía 13 años de edad. Fuimos siete hermanos, cinco hombres y dos mujeres, yo soy la sexta y la consentida de mi papá. La verdad es que no tengo historias tristes que contar de mi niñez, porque tuve una infancia muy linda. Éramos humildes y pobres, pero vivíamos felices. Éramos una familia muy unida. Mis muñecas eran de trapo, mi mamá nos las hacía, era bien buena para coser.

Lo que sí es que desde niña me tocó ver de cerca las arbitrariedades del ejército contra mi pueblo. Como mi papá era médico tradicional, mucha gente llegaba a consultarlo y mi casa siempre estaba llena de gente de las comunidades. Esto despertó sospechas de que pudiera estar organizando alguna célula guerrillera y un día el ejército se metió a mi casa con violencia, sin orden de cateo ni ningún papel que los autorizara a entrar a nuestro hogar. Eran los tiempos de la guerrilla de Lucio Cabañas y todos los indígenas y campesinos de la región eran considerados subversivos en potencia. En aquellos tiempos, el ejército estaba permanentemente en la región, pero la gente no los quería porque no respetaban, embarazaban a las muchachas, se las robaban a la fuerza. Les decíamos los “guachos". La gente les tenía mucho miedo, había muchas historias sobre ellos. Los soldados nunca trajeron paz a la región. ¡Siguen siendo terribles, represores! Siempre fueron arbitrarios. Detenían a la gente sin justificación, a mi papá lo agarraron varias veces, pero nunca le comprobaron nada y tuvieron que soltarlo. Era por eso que mi papá estaba en contra de la presencia militar en la zona. Él era una persona a la que le gustaba la paz, él me inculcó eso, decía que "siempre triunfan los que tienen la razón”. Tengo esperanzas de que esto sea cierto para México.

Algo que no me gustaba es que mi mamá era muy sumisa, era una mujer siempre atada a las decisiones de mi papá, pero hacia afuera era muy aguerrida, muy valerosa, estaba a la par de él en todas las luchas sociales. Yo creo que heredé el carácter de mi mamá. Había una cierta contradicción en la casa, porque con mi papá, mi mamá era muy sumisa, pero a nosotras nos enseñaba a ser mujeres fuertes, a no dejarnos. En la casa nunca se hicieron diferencias entre hijos e hijas. Nos criaron con el mismo derecho, incluso la tierra que papá nos dejó, nos correspondió por igual. Allá se acostumbra heredar sólo al hombre 
y mi papá decía que quería que tuviéramos algo seguro todos, hijos e hijas.

Recuerdo mi niñez, siempre rodeada de gente de las comunidades, mi casa era un espacio de encuentro, en donde no sólo se daban consultas médicas, sino apoyo solidario a quienes tenían problemas. Estos fueron los valores de solidaridad que heredé de mis padres y que han sido fundamentales para que me involucre en la lucha por la justicia.

Cuando éramos niños, la justicia y la seguridad de la comunidad estaban en manos de los "ronderos", que eran elegidos entre los hombres de la comunidad. Teníamos el "corral de consejos". Si los animales andaban sueltos haciendo daños, ibas a ver si estaba el animal en ese corral. Si se había comido las milpas del afectado, el dueño de los animales pagaba por los daños. A las personas que cometían algún delito o hacían disturbios las ponían a barrer la calle. En aquellos tiempos los problemas que enfrentaba la justicia comunitaria eran menores: el señor que agarraba la borrachera y se metía en pleitos o el marido que le pegaba a su señora. A estas personas se les ponía a barrer la calle, a limpiar el patio de la iglesia o a cortar leña. Eso hacía que les diera vergüenza y ya no lo volvieran a hacer, porque les daba pena y eso ayudaba. Nuestro sistema sí servía, porque había un sentido del honor muy profundo. La policía comunitaria que creamos ahora en Olinalá se propone recuperar muchos de esos valores.

\section{¿Las malas decisiones?}

A los 14 años de edad ya me consideraba una mujer y decidí huir con el papá de mis hijas, que se llama Miguel Rodríguez. Entonces se acostumbraba huir con el novio, luego pedías perdón y te casabas. Yo me casé sólo por la Iglesia, el 17 de marzo de 1986. A los 15 años ya era madre de la primera de mis tres hijas, Saira, después llegaron Ruby y Grisel. No entiendo porque tomé esa decisión, si en mi casa estaba bien y me consentían. Tuve que dejar de estudiar y luego enfrentar problemas de violencia doméstica vinculados con el alcohol. Miguel era campesino, trabajaba la tierra y un día me propuso que emigráramos a Estados Unidos con toda su familia, a buscar una mejor vida. Nos fuimos primero nosotros y dejamos a las niñas con mi familia.

Nos fuimos al estado de Washington y al principio nos quedamos con otra pareja de conocidos de Chilapa. El marido era muy borracho y Miguel empezó a tomar con él. Cuando estaban tomados se ponían muy violentos y nos encerraban a las dos mujeres en el baño. Logramos llevarnos a las niñas a los nueve meses de haber llegado, pero él siguió tomando, no conseguía trabajo. Yo era la que salía a trabajar y él se encargaba de nuestras hijas, pero no las cuidaba bien. Yo trabajé de todo: limpiando casas, luego en un hotel, en un club de golf, tenía hasta tres trabajos a la vez, trabajaba todo el día. De mesera ascendí a bartender, tomé cursos para ascender. Aquí en México empezaron los chismes, decían que trabajaba en una cantina. No se entiende que en Estados Unidos éste es un trabajo calificado y que uno tiene que capacitarse para ejercerlo.

Pero en la casa las cosas no iban bien, mi marido seguía tomando. Cuando yo le cuestionaba por qué las niñas no habían comido o estaban golpeadas, él se ponía violento. Lo peor fue la vez que nos sacó de la casa, llamó a migración y me acusó de robo. Yo me sentía muy vulnerable porque no tenía papeles. Un día, después de un episodio de violencia, la policía lo detuvo y estuvo preso nueve meses. Ése fue un parteaguas en mi vida porque las niñas y yo empezamos a recibir ayuda psicológica en un lugar que se llama Centro La Raza. En las sesiones de Consejo hablábamos de los derechos de las mujeres, de la importancia de la autoestima. Ahí decidí que no podía seguir en una relación violenta y que tenía que aprender a manejar para no depender de él. Aprendí sobre mis derechos y aprendí a defenderme. Después vino otra lucha para separarme y 
obtener pensión alimenticia. Esto me trajo más hostigamientos cuando Miguel salió libre. Nunca pagó la pensión completa, sólo 200 o 250 dólares, que no me alcanzaban para nada.

Las leyes progresistas de la ciudad de Seattle, que protegen a las mujeres víctimas de violencia, me apoyaron para obtener la nacionalidad estadounidense, eso me permitió regresar a México después de 13 años de ausencia. Yo había sufrido dos accidentes automovilísticos y vivía con dolor crónico, así que estaba considerando la posibilidad de regresar a Olinalá, donde mi pago por incapacidad podía servirme para abrir un negocio. Pero a mi regreso me encontré con otro tipo de violencia: la violencia del crimen organizado que tenía sitiado a Olinalá, cobraba "derecho de piso", actuaba con total libertad, asesinaba y secuestraba a quienes se negaran a acceder a sus demandas.

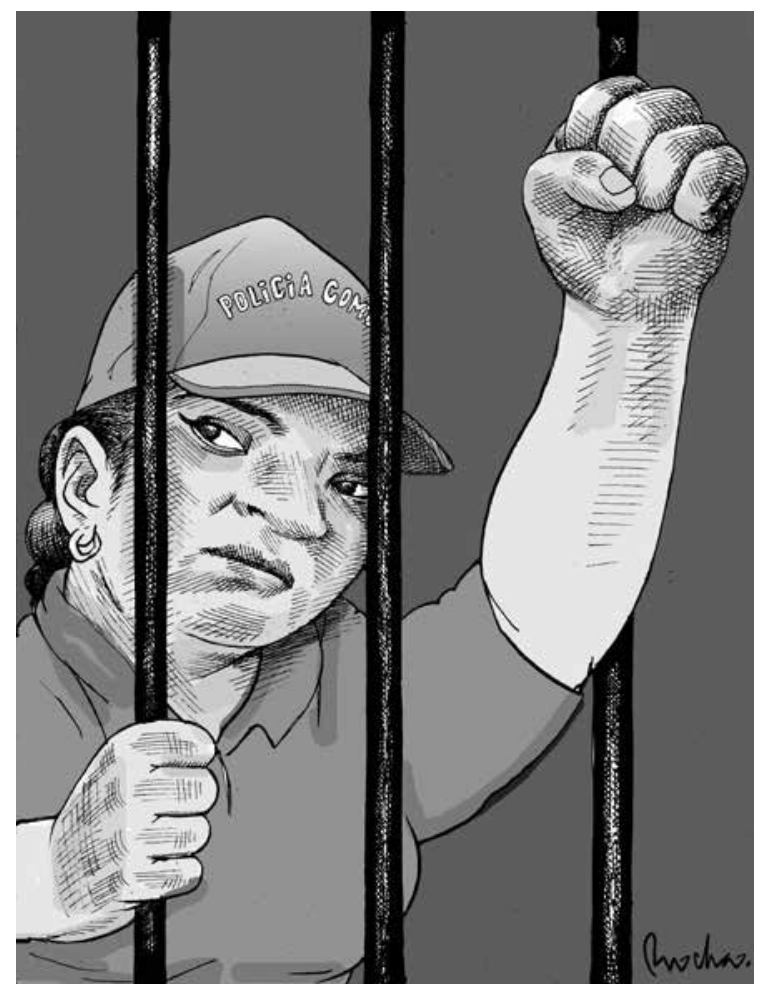

RochA - Nestora Salgado.

\section{De regreso en Olinalá}

Durante unos años estuve pasando un tiempo en Olinalá y otro en Seattle, donde se había quedado mi nueva pareja. Una de mis hijas, Saira, conoció a un joven de Olinalá y se casó. Las otras dos no se acostumbraron y decidieron regresarse. Al principio empecé a apoyar trayendo ropa de Estados Unidos para la gente más pobre y mucha gente venía a mi casa a buscar ayuda, apoyo para trámites. Puse una pequeña tienda, pero llegaban integrantes del crimen organizado a pedir "impuesto". Era secreto a voces en el pueblo que ellos actuaban con apoyo del presidente municipal. No se limitaban a pedir impuestos, empezaron a robar, secuestrar, se sabía que había redes de tráfico de mujeres y pornografía infantil. Había mucho miedo. Queríamos poner un alto a todo eso, pero no sabíamos qué hacer.

La gota que derramó el vaso fue el secuestro de un joven taxista en octubre de 2012. Después de tres días desaparecido lo encontraron muerto. El 27 de octubre de 2012 fue el día que llamamos la Rebelión de Olinalá. Repicaron las campanas y todos nos juntamos en la iglesia. Hacía 40 años que las campanas no sonaban así para llamar al pueblo. Todos sabíamos dónde vivían los sicarios y fuimos a buscarlos. Yo no entré al departamento en el que estaban, pero dicen que tenían a dos jovencitas drogadas semidesnudas, menores de edad, computadoras con pornografía infantil y celulares. Éstas eran pruebas de que se trataba de una red más amplia, así que tomamos la computadora y el celular y las entregamos al ejército, porque no confiábamos en la policía local. Tal vez el ejército también estaba coludido porque perdió las pruebas.

Cuando la gente estaba sacando a los sicarios del departamento, llegó la policía y los detuvo, pero lo único que hizo fue sacarlos de Olinalá. Pusimos retenes ciudadanos a la entrada del pueblo y establecimos guardias en todas las entradas del pueblo para evitar que entraran de nuevo. Empezamos siendo 
un movimiento ciudadano, recorrimos los barrios e invitamos a la gente a participar. Sabíamos que había todo un sistema de justicia indígena en otras regiones, que había logrado mantener al crimen fuera de sus comunidades: la Coordinadora Regional de Autoridades Comunitarias (CRAC). Primero invitamos a los policías comunitarios de Huamuxtitlán, una comunidad nahua que está cerca de Olinalá, y empezamos a organizarnos con ellos, pero nos interesaba ser parte de un sistema más amplio, que no fuera sólo de seguridad sino también de justicia, así que decidimos contactar a la CRAC.

En diciembre de 2012 invitamos a los coordinadores regionales de la CRAC, del municipio de San Luis Acatlán, a compartirnos sus experiencias en la construcción de un sistema de justicia basado en el derecho propio. A los dos meses de integrada la policía comunitaria de Olinalá, se realizó un taller de capacitación sobre la justicia indígena y los principios de funcionamiento de la CRAC. En este taller participaron unos 400 policías comunitarios, incluyendo mujeres y hombres ancianos de "conocimiento", algunos de los cuales habían participado en las Rondas Campesinas, existentes a principios del siglo pasado, y estaban familiarizados con los principios de la justicia indígena.

A partir de este taller, y mediante un proceso de consultas populares en asambleas barriales y visitas casa por casa, se cumplieron los requisitos impuestos por la CRAC. Este compromiso implicó asumir el "Reglamento interno del sistema comunitario de seguridad, justicia y reeducación de la Montaña y Costa Chica de Guerrero" como normatividad y vincularse a la Casa de Justicia de El Paraíso para el cumplimiento de los procesos de reeducación de los ciudadanos que cometieran delitos.

Así empezamos a funcionar. Hombres y mujeres participamos en la policía comunitaria, siguiendo el reglamento de la CRAC. Hicimos dos tomas de protesta, una con las autoridades comunitarias de la región y otra con autoridades comunitarias de El
Paraíso, para reafirmar nuestra adherencia a la CRAC de la Casa de Justicia de El Paraíso. Compramos nuestros uniformes y desfilamos por todo el pueblo para darnos a conocer.

En asamblea, fui elegida comandanta y eso me dio muchas responsabilidades, pero también me puso en el centro de los ataques de la Presidencia municipal y de otros grupos de poder, coludidos con el crimen organizado. La Presidencia municipal rechazaba a la CRAC porque decía que Olinalá no era una comunidad indígena, pero muchos de los que vivimos en la cabecera y en las comunidades somos indígenas. En el fondo, el presidente municipal y su gente tenían miedo de que fuéramos a interferir con sus "negocios". Pero nosotros nos amparamos en la Ley 701 del estado de Guerrero, que reconoce a la CRAC como un sistema de justicia y seguridad indígena legítimo.

La gente nos respetaba y nos venía a buscar cuando tenía algún problema. Nos coordinábamos con la Casa de Justicia de El Paraíso, adonde llevábamos a las personas que cometían algún delito. Las Casas de Justicia son los lugares en los que se lleva a cabo el proceso de reeducación de los detenidos por la policía comunitaria. La vigilancia de la Casa está en manos de un pelotón de policía de las comunidades y su comandante. Cada comunidad se turna y cubre también la alimentación de los reeducandos. Los detenidos hacen trabajo comunitario y no están encerrados, van a las comunidades a trabajar. También hay consejeros que les dan pláticas, se busca que reflexionen sobre sus acciones y pidan disculpas por sus errores.

Las cosas estaban funcionando bien y empezamos a tomar fuerza. Entonces, nos llama el secretario del gobernador Ángel Aguirre (2011-2014), para una reunión. Decidimos ir porque queríamos pedir que se construyera un centro de salud en Olinalá. En el camino nos perdimos y llegamos tarde, así que nos recibieron otros funcionarios, uno era su primo. Nos dijeron que el gobernador quería apoyar a la CRAC de Olinalá y que había dado órdenes de que 
nos dieran lo que necesitáramos. Ahí mismo nos entregaron una camioneta con el logotipo de la CRAC, 50 radios y 28 armas, que estaban en proceso de regulación en la Secretaría de la Defensa Nacional, y una antena repetidora. Las cosas estaban a mi nombre. De inmediato aclaré que yo iba en representación de la CRAC Olinalá y que todo debía darse a la CRAC. Yo sospechaba que era su manera de controlarnos y luego pude comprobar que estaba en lo cierto.

Cuando empezamos a desarticular las redes del crimen organizado en el municipio, comenzaron las llamadas. A partir de que detuve a unos jóvenes que estaban metidos en una red de tráfico de mujeres, me llamó el secretario del gobernador. Quisieron comprarme y yo lo hice público, eso les molestó mucho. Sofío Ramírez Hernández, entonces senador del Partido Revolución Democrática — que en la actualidad regresó al Partido Revolucionario Institucional- y mano derecha del gobernador Ángel Aguirre, me llamaba a diario, primero para que soltara a la gente que habíamos detenido y enviado al sistema de reeducación. Querían que los soltara a todos, pero la presión empezó por Eugenio, un tipo que estaba acusado de abigeato. Cuando detuvimos a los de la red de trata, me habló el procurador y también me dijo: "pida lo que quiera, pero vamos a darle paz al estado, libere a la gente, no queremos problemas". Me ofrecían vacaciones, camioneta blindada y siete millones de pesos. Y yo hice esa denuncia en la prensa. A partir de esta denuncia, se vinieron contra mí y los policías comunitarios.

El caso que detonó los problemas que vinieron después fue el de cuatro adolescentes que habían desaparecido por varios días, por lo que sus madres pidieron la intervención de la policía comunitaria de Olinalá para buscarlas. Las jóvenes fueron encontradas en otra comunidad y reconocieron que se habían ido de fiesta con dos hombres adultos. Debido a la presencia de redes de prostitución en la zona, sus mamás habían pedido por escrito a la CRAC que fueran enviadas lejos de la cabecera municipal para someterlas al proceso de reeducación, como una forma de protegerlas y alejarlas de las redes del crimen organizado que existen en el municipio. Estas jóvenes fueron enviadas al municipio de Ayutla de los Libres, bajo el resguardo de familias de la policía comunitaria. De ahí salió la acusación de secuestro agravado en mi contra. Luego me acusaron de haber secuestrado a todas las personas que estaban detenidas en la Casa de Justicia de El Paraíso, incluso aquellas que venían de otros municipios.

\section{Mi secuestro o presunta detención y la experiencia de la cárcel}

Sofío Ramírez me habló dos días antes de mi detención y me dijo: "mira, suelta a esta gente; si no, atente a las consecuencias". Entonces lo reté y le dije: "yo no me vendo, si yo no ando ahí por el dinero". Ellos querían controlarnos, que no nos metiéramos con sus intereses. Yo sentía que tenía la fuerza del pueblo, los confrontaba porque sentía que no podían hacer nada contra nosotros. De tonta, pensaba: "yo tengo el poder del pueblo y el pueblo me apoya", decía. Después supe que ese poder no era suficiente.

El 22 de agosto de 2013, unos 500 militares llegaron a la Casa de Justicia de El Paraíso y liberaron a las personas que estaban en proceso de reeducación, entre ellos los delincuentes involucrados en el tráfico de mujeres. A la vez que liberaban a los delincuentes, detuvieron a los 20 policías comunitarios que estaban de guardia y al comandante Bernardino García Francisco. Ese mismo día a las 6:00 de la tarde, marinos, militares y miembros de la Policía Federal Preventiva me secuestraron cuando iba rumbo a la gasolinera del pueblo adonde me dirigía con mi sobrino, que también era miembro de la policía comunitaria, a cargar combustible.

Al detenerme, me subieron a un carro de la Marina y me trasladaron a la ciudad de Chilpancingo 
con una custodia del Ejército. Al llegar a la ciudad, me detuvieron unos 40 minutos, porque ni la Marina ni el Ejército querían entregarme a la Procuraduría General de Justicia del Estado de Guerrero, porque no traían orden de aprehensión y ellos sabían que estaban haciendo algo ilegal. En los documentos aparece que un policía ministerial hizo la puesta en disposición ante la Procuraduría, pero eso es falso, porque nunca lo vimos. Aparentemente, era una orden extrajudicial. Ni la Marina ni el Ejército tenían un documento oficial para detenerme, la orden venía de más arriba, no sé si del gobernador o de quién. En Chilpancingo sólo me revisó un médico legista, que dio fe de que no me habían golpeado, y después me mandaron a Acapulco en un helicóptero.

Ya en Acapulco, ningún órgano de justicia, ningún ministerio público me recibió. No estuve a disposición de ninguna autoridad judicial. Me llevaron a un centro de detención clandestina. En ese momento pensé que me iban a matar o desaparecer, era evidentemente un secuestro, no una detención legal. No había representante de ninguna instancia de justicia. Yo sabía que tendrían que ponerme a disposición de la Procuraduría General del Estado, pero hasta ahora todo había tenido las características de un secuestro, no de una detención. Escuché que me llevarían a Tepic, Nayarit. Me subieron a una camioneta blindada, custodiada por el Ejército, la Marina y la Policía Federal, para ir a los hangares en los que el gobernador tenía su avión. Cuando estábamos en camino, recibieron una llamada. No sé quién era, pero les preguntó si yo ya había hecho la declaración preparatoria. Evidentemente, yo no había hecho nada. Sé que recibieron instrucciones de que me tomaran una declaración. Querían volver legal algo que a todas luces era ilegal.

Entonces nos regresamos y fuimos a los juzgados de la prisión de Acapulco. Es el lugar al que llevan a los presos a declarar, pero yo nunca estuve presa ahí. Yo estuve en un centro de detención clandestino. Ahí encontré a un agente del ministerio público que conocía por mi trabajo como autoridad y le expliqué lo que estaba pasando. Él me dijo: "son órdenes que vienen de arriba y yo tengo que obedecer”. Ahí pedí que llamaran a la Embajada de Estados Unidos, pues sabía que como ciudadana estadounidense tenía derecho a apoyo consular. Ahí di por primera vez mi declaración, y dije lo mismo que dije a todo lo largo de mi proceso; fueron los mismos argumentos que después llevaron a mi liberación: que yo estaba cumpliendo con mis responsabilidades como autoridad comunitaria bajo el respaldo de la Ley 701 del estado de Guerrero y el artículo segundo constitucional, que reconoce nuestros derechos como autoridades comunitarias. Pero no podía presentar pruebas, porque evidentemente no las llevaba conmigo y no me dejaron tener abogado. Mi detención estuvo llena de irregularidades, en cada paso se violaron mis derechos. De ahí me pasaron a la prisión de Acapulco a hacer la ficha de detención y me quitaron todas mis pertenencias. Después pude ver en mi expediente que argumentaron que yo había estado detenida en esa prisión, pero ésa fue una más de las mentiras que tejieron en torno a mi detención.

En Tepic me recibió la Policía Federal y me llevaron a la cárcel de alta seguridad de El Rincón, Nayarit. Ahí me dieron un uniforme y finalmente me tomaron una declaración. Me exigieron que dijera cuál era mi delito. Les volví a aclarar que era una autoridad comunitaria y que no había cometido ningún delito. La directora, al escucharme, me llevó aparte y yo le expliqué la situación, le conté que era de la policía comunitaria y que hay leyes en el estado de Guerrero que amparan nuestro trabajo. Ella me escuchó, pero me dijo: “usted está detenida por secuestro y yo tengo la obligación de mantenerla presa”. Me hicieron de nuevo la ficha y empezó un infierno que duró un año y nueve meses, en las peores condiciones penitenciarias, que no le deseo a nadie. Me pasaron primero al sistema 
de clasificación, pero la psicóloga que me entrevistó inducía mis respuestas. Empezó preguntándome: “¿por qué secuestraste?”. Le aclaré que no era secuestradora, que ella no estaba ahí para juzgarme. Yo sabía mis derechos y también sabía que no era ético lo que ella hacía. Hablé de mi trabajo a favor de la vida y los derechos de los pueblos. Ella tomó mis críticas como rebeldía, me clasificó como "narcisista" y me pusieron en una celda de aislamiento total. Es tan terrible el uso que hacen los psicólogos de la información que les sacan a los detenidos, que son parte de un aparato de tortura. En mi caso, cuando en una entrevista hablé de mi miedo a la oscuridad, esto fue aprovechado para ponerme en una celda sin luz, en pésimas condiciones y aislada de las demás. Después de varios meses, trajeron a una mujer que estaba castigada y la pusieron a un lado de mí, pero no podíamos vernos ni hablarnos, estábamos separadas por una pared. Las condiciones tan terribles de aislamiento en las que me tenían fueron denunciadas por mi familia y gracias a esta presión logré que me pasaran a otro piso, con más luz, pero aún sola. Era el segundo piso del edificio, en el que estaban las mujeres con hijos. Seguía aislada y no tenía actividades, no podía salir al patio. Me tomaban fotos falsas en las que me ponían en una mesa con materiales para aparentar que estaba integrada a las actividades del penal. Esas fotos las mostraban afuera para decir que yo estaba en buenas condiciones, casi como si estuviera en un spa.

Otra forma de tortura que sufrí y que pudo haberme costado la vida, es que se me negó el acceso al agua potable. Eso fue terrible. Todas las internas tenían derecho a un garrafón de agua menos yo. No

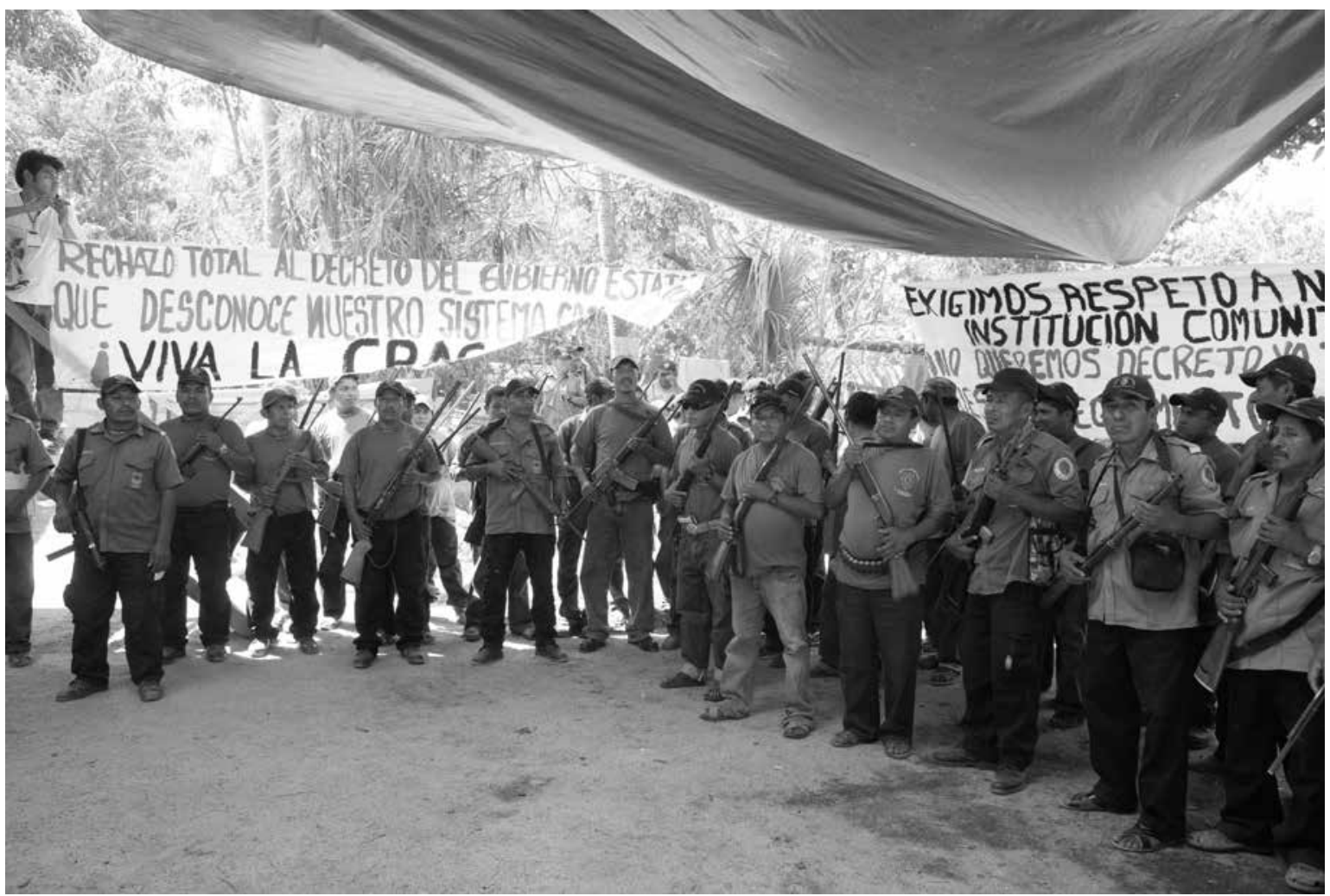

Prometeo Lucero • Encuentro Estatal de Justicia Comunitaria, San Luis Acatlán, Guerrero, 17 de febrero de 2013. 
se me permitía tener acceso a un abogado, todos mis derechos se seguían violando. A los ocho meses de haber llegado a ese penal, llegó el abogado Emiliano Gómez Montt. Fue el primer abogado con el que tuve contacto, pero sólo llegó porque quería conocerme, no era mi representante legal y no se le permitió pasar, sólo verme a través de las rejillas.

$\mathrm{Al}$ año de estar presa, me sacaron a los juzgados y me avisaron que un juez federal había dictado un auto de libertad inmediata, porque no se había podido configurar el delito de "delincuencia organizada con fines de secuestro”. Yo estaba feliz, pero no pasó nada, no me liberaron. A las semanas, mientras esperaba ser liberada, me sacaron de nuevo a los juzgados y me avisaron que me estaban acusando de otros secuestros. Alguien se había movido de nuevo para evitar que me liberaran. Todo se seguía alargando y mi salud se deterioraba más cada vez. Yo digo que fui juzgada dos veces por el mismo delito, porque no cambiaron los argumentos, el lugar ni la forma.

El tiempo que pasé en la cárcel de seguridad de Tepic fue como estar en el infierno. La gente que trabaja en ese lugar es como sacada del infierno, ha pasado por un proceso de deshumanización que los hace actuar sin escrúpulos. Fueron 21 meses de tortura psicológica. No me dejaban dormir, la guardia pasaba varias veces en la noche a hacer ruido en las rejas para despertarme. Realmente se trata de lugares de castigo y tortura, nada que ver con readaptación o rehabilitación. Pero como dice el dicho: "lo que no te mata, te fortalece", y eso pasó conmigo. Salí fortalecida, sentía que en cualquier momento me podían matar y llegó un momento en que perdí el miedo. Cuando pierdes el miedo, lo único que queda es el valor. A lo único que le tenía miedo era a la cárcel y a la muerte, y ya las enfrenté a las dos. Si lo que querían era quebrarme, se equivocaron, me fortalecieron, y aquí estoy hoy, más fortalecida que antes.

\section{Tras la liberación}

Después de casi dos años de prisión en Nayarit, durante los cuales fui torturada psicológicamente, no se me permitió tomar agua purificada y me mantuvieron en aislamiento total, con los ciclos de sueño interrumpidos, tomé la decisión de hacer una huelga de hambre para exigir mi libertad y la de mis compañeros de la CRAC. Esta huelga de hambre, que casi me cuesta la vida, logró hacer presión en las autoridades judiciales que ordenaron mi traslado a la Torre Médica de Tepepan, en la Ciudad de México, el 25 de mayo de 2015. Ahí estuve diez meses más, atendiendo mi salud, que se había deteriorado muchísimo. Tras el maltrato vivido en Nayarit, el dolor crónico producto de mis accidentes automovilísticos había regresado. Fue ahí, en Tepepan, donde conocí a Aída Hernández y empezamos armar la historia que hoy comparto con ustedes y que fue la base del peritaje que elaboró para mi defensa.

Salí libre el 18 de marzo de 2016. Muchas fuerzas se unieron para lograr mi libertad. Mi abogada Alejandra Gonza, en Estados Unidos, llevó el caso a las Naciones Unidas y a la Comisión Interamericana de Derechos Humanos (Proceso, 3 de febrero de 2016). Hubo mucha gente solidaria que demandó mi liberación con campañas nacionales e internacionales. Se formaron comités con el nombre "Free Nestora" en varias entidades de Estados Unidos. En México, mis abogados, Leonel y Sandino Rivero, apoyados con el peritaje realizado por Aída Hernández Castillo y Héctor Ortiz Elizondo, fueron fundamentales para lograr mi excarcelación.

Al salir, los representantes del gobierno me amenazaron de forma velada y me obligaron al exilio. Me dieron sólo cuatro días para estar en el país. La decisión de irme no fue realmente mía, yo ni siquiera me quería venir a Estados Unidos, quería seguir trabajando en mi comunidad y para mi comunidad. El hecho de decir "no hay garantías de seguridad, no podemos garantizar tu vida si te 
quedas en México, te tienes que salir del país", fue una amenaza casi directa. Me plantearon: "tienes que salirte del país, no podemos hacernos cargo de tu seguridad, te van a matar, si quieren atacar al gobierno te van a matar a ti, si quieren atacar a la comunidad te van a matar a ti”. O sea, no me quedó de otra. Antes de venirme a Seattle, Washington, reuní a muchas organizaciones en el Centro Agustín Pro, a las esposas de los presos políticos, representantes de la policía comunitaria, mi familia, y les propuse venirme a Estados Unidos y continuar una campaña aquí. Les expliqué que no me podía quedar en México, pero que no me quería quedar sentada, que quería seguir trabajando y que la lucha era por los compañeros que estaban presos. Ahí diseñamos la campaña "Pon nombre y rostro a los presos políticos de México", pensando en hacer una campaña internacional fuerte y lograr lo que se había logrado conmigo: articular fuerzas nacionales e internacionales para mi liberación. Me vengo a Estados Unidos con esa seguridad, con esa fortaleza, porque me sentí fortalecida al tener la convicción de que no estaba sola, que tenía a las organizaciones que apoyaban y respaldaban nuestra lucha.

Sólo tomé unos pocos días de descanso con mi familia en Seattle, Washington, y comencé la campaña en Los Ángeles. Mandé a hacer una manta con los rostros y nombres de mis compañeros. Al principio todo parecía bien, estábamos unidos y teníamos la convicción de que íbamos a lograr su liberación. Después vino el viaje a Europa, estuve en España y Alemania, llevando sus testimonios y denunciando la criminalización de la justicia indígena, demandando el respeto a la Ley 701 que reconoce nuestros sistemas de justicia y nuestros derechos como pueblos. No hablaba en mi nombre, sino a nombre de todos los pueblos indígenas de México que están sufriendo el impacto terrible de la militarización, la criminalización y la violencia en sus territorios. Fuimos construyendo una red de aliados a través de las fronteras. Me reuní con comunidades kurdas, que también tienen sus policías comunitarias, con pueblos nativo-americanos en Alaska y Canadá. Fuimos construyendo una fortaleza grande para apoyarnos en nuestras luchas. En Phoenix, Arizona, nos reunimos con diferentes grupos de nativoamericanos de Estados Unidos y llegaron también representantes de organizaciones de Latinoamérica. Llegaron los compañeros ambientalistas hondureños que trabajaban con Bertha Cáceres.

Por medio de las redes sociales, construimos alianzas con organizaciones guatemaltecas y colombianas que también trabajan por la defensa de sus territorios. Cada vez que yo iba a un lugar, se publicaba en las redes sociales algún ataque en mi contra, que era retomado por algunos medios de comunicación. Se fueron haciendo chismes en mi contra, con el propósito de dividirnos y debilitar nuestras luchas. Me atacaron diciendo que estaba lucrando con los presos políticos, cuando jamás recibí un centavo en su nombre, ni siquiera para comprar boletos de avión, porque las organizaciones solidarias los compraban por mí. Estos chismes afectaron mi relación con los compañeros presos, que finalmente hicieron declaraciones en las que me desconocieron. Me dolió muchísimo, no sólo porque me sentí lastimada personalmente, sino porque estas divisiones afectan nuestras luchas e impiden que podamos avanzar. Abandoné la campaña por su liberación y ellos, lamentablemente, continúan presos.

\section{Las nuevas luchas del otro lado de la frontera}

He trabajado todos estos años por mi pueblo, porque creo en la importancia de la organización y de la defensa de nuestros derechos. Nunca he participado en ningún partido político. Si lo hubiera hecho por mi propio interés, ya tendría algún cargo o algún beneficio personal. Pero aquí sigo, viviendo en mi departamentito, con mi marido, hasta ahora no he aceptado ninguna invitación a participar en ningún 
partido. No creo que algún partido o candidato nos vaya a salvar y tampoco que la solución de nuestros problemas vaya a venir del gobierno. Creo en la autogestión, en la lucha por la autonomía indígena, en la fuerza de la organización colectiva, pero debemos estar unidos para lograrlo y ése ha sido el gran reto. Lo que he vivido, el desconocimiento que hacen los presos políticos a la campaña por su liberación, también es producto de las divisiones que hay en la policía comunitaria. Esto me da mucha tristeza, nos debilita como pueblos. La idea de crear en Olinalá la Casa de Solidaridad Nestora Salgado era tener un espacio para rearticularnos y seguir trabajando juntos. Para que la gente de las comunidades que tenga que ir a Olinalá al médico, tenga un lugar adonde llegar. Quería crear un espacio comunitario para los pueblos, pero los ataques contra mi persona y las divisiones no han permitido que este espacio se eche andar. Hemos recibido amenazas, pusieron una cabeza de perro muerto en la puerta, con un cartel insultándome. Mi hija, que vive en Olinalá, tiene miedo. De momento, los compañeros de la policía comunitaria están cuidando la casa, pero no se han podido impulsar los planes que teníamos para ese espacio.

Hay muchas luchas y muchas necesidades, más ahora con la presidencia de Donald Trump, que está afectando a muchos de mis paisanos en Estados Unidos. Sigo trabajando por la justicia con organizaciones a ambos lados de la frontera. No quiero problemas ahorita con los compañeros de Guerrero, pero sí sé que hay mucho preso político que nos necesita y que los presos políticos son de México, que no tienen dueño y merecen que los defendamos, que haya gente que hable por ellos y que esté lista para respaldar a cualquier preso político, en cualquier momento. Al mismo tiempo, me he involucrado en la defensa de los migrantes indocumentados que ahora viven con miedo de ser deportados y que sus familias queden divididas.
He continuado el trabajo en el ámbito de la justicia, participando en los Tribunales del Pueblo, que son tribunales éticos que se han creado para juzgar las violaciones a los derechos humanos de los migrantes, los pueblos nativo-americanos y otros sectores oprimidos. Nos reunimos en Phoenix el 18 de marzo de 2017 para conmemorar mi primer año de libertad, para decirles a las autoridades que no estamos de acuerdo con que la policía colabore con los agentes de migración y con que detengan a las personas sólo por ser latinas, y a los 15 minutos las estén entregando a migración. Exigimos una audiencia con las autoridades y hubo una reunión muy grande con la jefa de la policía de Phoenix, la gente de la comunidad y los representantes de los colectivos. Se les exigió un alto a la criminalización de la población migrante. He participado también en Tribunales del Pueblo, en Tacoma y Olimpia, aquí en el estado de Washington, en los que se han presentado casos de criminalización de población migrante. He participado como juez en estos tribunales. También he entrado a cárceles a entrevistar presas latinas y he sacado sus voces, sus denuncias. Me entrevisté con mujeres muy pobres, que no hablan inglés y muchas veces no saben por qué están presas. Muchas de estas mujeres han estado detenidas sin juicio, por años. Una de las señoras que me tocó entrevistar ya tiene tres años presa y no llega su juicio. Sus historias me recuerdan lo que yo viví en México. En Estados Unidos también hay cosas que se hacen ilegalmente. La señora está ahí, presa, sin tener un juicio justo; ni la sentencian, ni la sacan. Eso es lo que nosotros estamos peleando, procesos que sean justos. Siento que estoy dándole continuidad al trabajo que comencé en la policía comunitaria de Olinalá, ahora del otro lado de la frontera, con mis paisanas presas.

Yo sigo trabajando, hay mucho que hacer, mucho que organizar, y gracias a Dios tengo la posibilidad de hacerlo, mi esposo me apoya. Estoy 
compartiendo lo que he aprendido en todos estos años de lucha para promover la organización de mi gente en Estados Unidos.

El compromiso con mi gente en México sigue en pie. Ahora que celebramos el año de mi liberación me reuní con Mario Luna, representante del pueblo yaqui que fue preso político al mismo tiempo que yo y que ha luchado por la defensa de su territorio. También apoyé a la periodista Anabel Hernández y la acompañé en las presentaciones de su libro más reciente, La verdadera noche de Iguala (2016), en el que denuncia la participación del gobierno en la desaparición de los 43 estudiantes de Ayotzinapa.

También me he articulado con las organizaciones de madres de desaparecidos. En mayo de 2017 organicé una gira en Estados Unidos y Canadá de dos de las representantes de Las Buscadoras de El Fuerte Sinaloa. Todas ellas han sido víctimas de la violencia y la impunidad que caracteriza a los gobiernos en México. Es muy triste lo que sigue sucediendo en nuestro país. Estamos en una balanza: los que queremos justicia y los que apoyan y se benefician de la corrupción. Es una balanza muy dispareja. Está más arriba la impunidad, la corrupción, y no nos dejan a avanzar en nuestra lucha, porque la impunidad y la corrupción están más fuertes, entonces meten a su gente a destruir los movimientos que se hacen o la organización de los pueblos en contra de la impunidad. Tenemos que ser capaces de superar nuestras diferencias y trabajar unidas, para que esta balanza no esté tan dispareja. Ellos le apuestan a nuestras divisiones para debilitarnos.

Quiero aprovechar este testimonio para llamar a las policías comunitarias a la unidad, a las organizaciones de pueblos indígenas a la unidad, a las madres de los desaparecidos a la unidad. Sólo unidas y unidos vamos a lograr parar esta ola de muerte e impunidad que está arrasando a nuestro país. D

\section{Bibliografía}

Hernández, Anabel, 2016, La verdadera noche de Iguala. La historia que el gobierno quiso ocultar, Grijalbo, México.

Hernández Castillo, Rosalva Aída, 2017, “Activismo legal y las paradojas de la antropología jurídica feminista”, en Rosalva Aída Hernández Castillo (coord.), Resistencias penitenciarias. Investigación activista en espacios de reclusión, Grupo Internacional de Trabajo sobre Asuntos Indígenas/Colectiva Editorial Hermanas en la Sombra/Libera Desarrollo Humano/Juan Pablos, México, pp. 51-82. inédito, "The Paradoxes of Expert Witness Reports in the Defense of Indigenous Justice Systems: The Case of Nestora Salgado García".

Proceso, 2016, "La detención de Nestora es 'ilegal y arbitraria': onu”, núm. 2128, 3 de febrero, pp. 30-48. 